\title{
Reliability of a participant-friendly fecal collection method for microbiome analyses: a step towards large sample size investigation
}

Joanna W. Szopinska ${ }^{1 \dagger}$, Raphaële Gresse ${ }^{2 \dagger}$, Saskia van der Marel ${ }^{3}$, Jos Boekhorst ${ }^{4}$, Sabina Lukovac ${ }^{4}$, Iris van Swam ${ }^{4}$, Barbara Franke ${ }^{1,3}$, Harro Timmerman ${ }^{4}$, Clara Belzer ${ }^{5}$ and Alejandro Arias Vasquez ${ }^{1,3,6^{*}}$ (D)

\begin{abstract}
Background: The effects of gut microbiota on human traits are expected to be small to moderate and adding the complexity of the human diseases, microbiome research demands big sample sizes. Fecal samples for such studies are mostly self-collected by participants at home. This imposes an extra level of complexity as sample collection and storage can be challenging. Effective, low-burden collection and storage methods allowing fecal samples to be transported properly and ensuring optimal quality and quantity of bacterial DNA for upstream analyses are necessary. Moreover, accurate assessment of the microbiome composition also depends on bacterial DNA extraction method. The aim of this study was to evaluate the reliability and efficiency of the OMNIgene.GUT kit as a participant-fecal friendly collection method (storage at room temperature for $24 \mathrm{~h}(\mathrm{O} 24 \mathrm{~h})$ or 7 days $(\mathrm{O} 7 \mathrm{~d})$ ) in comparison to the standard collection method (Fresh, storage at $4{ }^{\circ} \mathrm{C}$ for less than $24 \mathrm{~h}$ ) in terms of amount of variability and information content accounting for two common DNA extraction methods.
\end{abstract}

Results: Fourteen fecal samples were collected from healthy individuals (7 males, 7 females). Collection and storage methods did not differ significantly in terms of DNA concentration and Shannon diversity index. Phylum relative abundance showed significant differences for Bacteroidetes, Actinobacteria and Cyanobacteria. The differences were observed between control (Fresh) and O24h methods, but not between Fresh and O7d. These differences were not seen when performing bacterial DNA quantification based on three bacterial groups: Bacteroides spp., Bifidobacterium spp. and Clostridium cluster IV, which represent three major phyla: Bacteroidetes, Actinobacteria and Firmicutes respectively. The two DNA extraction methods differ in terms of DNA quantity, quality, bacterial diversity and bacterial relative abundance. Furthermore, principal component analysis revealed differences in microbial structure, which are driven by the DNA extraction methods more than the collection/storage methods.

Conclusion: Our results have highlighted the potential of using the OMNIgene.GUT kit for collection and storage at ambient temperature, which is convenient for studies aiming to collect large samples by giving participants the possibility to send samples by post. Importantly, we revealed that the choice of DNA extraction method have an impact on the microbiome profiling.

Keywords: Microbiome, OMNlgene•GUT, Bacterial DNA extraction, Next generation sequencing, Fecal collection and storage method

\footnotetext{
* Correspondence: Alejandro.AriasVasquez@radboudumc.nl

${ }^{\dagger}$ Joanna W. Szopinska and Raphaële Gresse contributed equally to this work.

'Department of Psychiatry, Radboudumc, Donders Institute for Brain,

Cognition and Behaviour, P.O. Box 9101 HB, Nijmegen, The Netherlands

${ }^{3}$ Department of Human Genetics, Radboudumc, Donders Institute for Brain,

Cognition and Behaviour, P.O. Box 9101 HB, Nijmegen, The Netherlands

Full list of author information is available at the end of the article
}

(c) The Author(s). 2018 Open Access This article is distributed under the terms of the Creative Commons Attribution 4.0 International License (http://creativecommons.org/licenses/by/4.0/), which permits unrestricted use, distribution, and reproduction in any medium, provided you give appropriate credit to the original author(s) and the source, provide a link to the Creative Commons license, and indicate if changes were made. The Creative Commons Public Domain Dedication waiver (http://creativecommons.org/publicdomain/zero/1.0/) applies to the data made available in this article, unless otherwise stated. 


\section{Background}

The human gastrointestinal tract houses a highly complex ecosystem composed of ten to one hundred trillion microbial cells called the gut microbiota [1]. Gut microbes play an important role in human health by providing important metabolic, immunological and developmental functions [2, 3]. Recent studies have suggested a link between changes (i.e. dysbiosis) in the human gut microbiota and a wide variety of diseases and syndromes including obesity, irritable bowel syndrome, allergies, liver and skin diseases as well as neurodevelopmental disorders [4-6]. Microbiota-based therapies are now considered a non-pharmacological treatment alternative for several metabolic and immune related disorders [7], and may offer promise suggested for neuropsychiatric disorders [8].

An accurate analysis of the microbiome structure, in relation to human traits and diseases, at the population level, relies on large sample sizes. This facilitates analysis with adequate statistical power and limit the influence of outliers and extreme observations [9-11]. However, current methods of collecting fecal samples demand high involvement from participants to set up appointments on the collection day and storing the samples in their own fridge or freezer, which can bring discomfort for the participants and potentially represent a health risk. Those factors might negatively affect participants' decision to take part in a study. Most times, immediate freezing needed in the standard collection method may be not feasible [12]. Recently, more elegant methods for sample collection and early storage have been developed. Here, we tested a commercial kit (OMNIgene•GUT) which allows collection and storage of fecal samples at room temperature (RT). Use of such kits enables participants to send their samples via regular post without the need of making appointments, refrigeration, or coldchain transportation and might increase participation for (future) research studies.

Collection, sample storage and bacterial DNA extraction methods are key steps required for the accuracy of the studies of human intestinal microbiota composition without (minimal) loss of any taxa [13]. If immediate processing of samples is not feasible (i.e. geographical distances or temperature and storage requirements), microbial community representation might be affected. The technical sources of variation (i.e. sample collection and storage techniques, DNA extraction method) have a large influence on the observed structure of the microbial community, often on scales similar to or larger than biological effects [14]. In the present study we tested differences in microbiome profile determined by two different commercial DNA extraction methods, QIAamp DNA Mini Kit (QIA; QIAGEN, Venlo, NL) and PowerFecal ${ }^{\odot}$ DNA Isolation Kit (PF; MO BIO Laboratories, Inc.).
The aim of the study was a two-fold: (i) to test the OMNIgene.GUT (DNA Genotek, Ottawa, CA) feces collection and storage kit in terms of DNA quality and quantity, bacterial diversity and composition based on the quantification of genes coding for $16 \mathrm{~S}$ ribosomal RNA (rRNA), and to compare it to the standard collection and storage method (called here the 'Fresh' method) and (ii) to determine the collection and storage method while accounting for two common DNA extraction methods, QIAamp DNA Mini Kit (QIA) and PowerFecal ${ }^{\odot}$ DNA Isolation Kit (PF). We addressed DNA extraction method issue because it is a part of overall efficacy of collection strategy.

\section{Methods}

\section{Sample collection, storage and DNA isolation}

All participants included in this study were adults $(18<)$. Fecal samples were collected from 14 healthy individuals (7 males, 7 females) in triplicate $(1 \times$ Fresh, $2 \times$ OMNIgene.GUT, $N=42$ ). The first group of samples collected via the Fresh method was stored at $4{ }^{\circ} \mathrm{C}$ right after collection and processed within $24 \mathrm{~h}$. The other two groups of samples were collected using the OMNIgene•GUT kit (DNA Genotek, Ottawa, CA) and kept at room temperature (RT) up to $24 \mathrm{~h}(\mathrm{O} 24 \mathrm{~h})$ or 7 days $(\mathrm{O} 7 \mathrm{~d})$ and then continue with DNA extraction (Additional file 1: Figure S1). The total amount of sample used (from the OMNIgene.GUT kit) for DNA extraction was $0.25 \mathrm{~mL}$ containing approximately $50 \mathrm{mg}$ feces and $200 \mu \mathrm{L}$ stabilizing liquid. DNA was extracted using QIAamp DNA Mini Kit (QIA; QIAGEN, Venlo, NL) according to the manufacturer's instructions, including bead-beating steps using a FastPrep ${ }^{\oplus}-24$ Instrument (MP Biomedicals, Amsterdam, NL). To compare the effects of two different DNA extraction methods, DNA from the O24h samples was also isolated using PowerFecal $^{\circ}$ DNA Isolation Kit (PF; MO BIO Laboratories, Inc.) recommended by DNA Genotek (Ottawa, CA) (Additional file 2: Figure S2). DNA extraction procedures were performed at NIZO food research (Ede, NL).

Given our aim and that we had two DNA extraction approaches we decided to test their efficacy and efficiency on the samples collected with the OMNIgene.GUT kit and stored for $24 \mathrm{~h}(\mathrm{O} 24 \mathrm{~h})$ because these should, in principle, conserve the bacterial DNA better as those stored for 7 days $(\mathrm{O} 7 \mathrm{~d})$. This decision was made prior to the sequencing experiments and analysis. The PF method was tested as recommendation by the manufacturers of the OMNIgene.GUT. The QIA method came as a recommendation from our co-authors from NIZO which have extensive experience with bacterial DNA extraction.

\section{PCR amplification and sequencing}

The PCR amplicons of bacterial 16S rRNA V3-V4 regions were generated using 2-step polymerase chain reaction 
(PCR). Universal primers with adaptor sequences for use in Illumina MiSeq assays were used for an initial amplification of the V3-V4 part of the 16S rRNA gene with the following sequences: forward primer '5-CCTACGGGA GGCAGCAG-3' (primer 357F); reverse primer '5-TACN VGGGTATCTAAKCC' (adapted 802R). PCR amplification mixture contained: $1 \mu \mathrm{L}$ of template DNA, $1 \mu \mathrm{L}$ of the forward primer $(10 \mu \mathrm{M} ; 357 \mathrm{~F}), 1 \mu \mathrm{L}$ of the reverse primer $(10 \mu \mathrm{M} ; 802 \mathrm{R}), 1 \mu \mathrm{L}$ KOD Hot Start DNA Polymerase ( $1 \mathrm{U} / \mu \mathrm{L}$; Novagen, Madison, WI, USA), $5 \mu \mathrm{L}$ KOD-buffer (10×), $3 \mu \mathrm{L} \mathrm{MgSO} 4(25 \mathrm{mM}), 5 \mu \mathrm{L}$ dNTP mix $(2 \mathrm{mM}$ each), and $33 \mu \mathrm{L}$ nuclease-free water (total volume $50 \mu \mathrm{L}$ ). Reactions were held at $95{ }^{\circ} \mathrm{C}$ for $2 \mathrm{~min}$ followed by 30 cycles at $95{ }^{\circ} \mathrm{C}$ for $20 \mathrm{~s}, 55^{\circ} \mathrm{C}$ for $10 \mathrm{~s}$, and $70{ }^{\circ} \mathrm{C}$ for $15 \mathrm{~s}$. The PCR amplicons of approximately $500 \mathrm{bp}$ were subsequently purified using the MSB Spin PCRapace kit (Invitek, STRATEC Molecular GmbH, Berlin, DE). Concentration and quality were subsequently checked by using 2000 spectrophotometer (Thermo Scientific, Breda, NL). Purified PCR products were shipped to BaseClear BV (Leiden, NL) and used for the second PCR in combination with sample-specific barcoded primers. DNA was used for PCR amplification at a concentration of $8 \mathrm{ng} / \mu \mathrm{L}$. PCR products were purified using the Mini Elute PCR Purification kit (QIAGEN, Venlo, NL). Amplicon libraries were normalized based on their $\mathrm{ng} / \mu \mathrm{L}$ concentration, after which the $\mathrm{pM}$ concentration of the pool was determined using the Kapa Illumina library Quantification kit. Final loading concentration of the libraries on the MiSeq was targeted at $5.5 \mathrm{pM}$ with a 10\% PhiX spike. All samples were processed and prepped at the same time and ran on a single Illumina lane. Sequencing of libraries was performed with Illumina MiSeq platform with the paired-end (2x) 300 bp protocol. We used FASTQC and the Illumina CASAVA pipeline (v1.8.3) to achieve high-quality sequences as described in PMID28774885 [15].

\section{Processing of sequencing data and statistical analysis}

Read pairs were assembled into pseudoreads with PEAR, using the default settings [16]. Sequence data was analyzed using a workflow based on the software tool QIIME (Quantitative Insights Into Microbial Ecology) version 1.8 [17]. Reference-based chimera removal was done using UCHIME as implemented in QIIME 1.8. OTUs consisting of only a single sequence were removed. Sequences that could not be aligned by PyNAST against the $16 \mathrm{~S}$ reference alignment were removed. Operational taxonomy units (OTU) clustering (open reference), taxonomic assignment and reference alignment was done with the 'pick_open_reference_otus.py' workflow script of QIIME, using 'UCLUST' as clustering method (97\% identity) and Greengenes version 13.8 as a reference [18]. Sequence depth per sample was investigated by comparing the read counts between three different collection methods and two different DNA extraction methods. Alpha diversity was calculated using the 'alpha_rarefaction.py' workflow script. Reference-based chimera removal was done with UCHIME [19]. The Ribosomal Database Project (RDP) classifier version 2.2 was performed for taxonomic classification. In order to compare samples to each other we transform the read counts into relative abundance (normalization step). Taxa-specific read counts were divided by the total number of reads for that sample to which taxa belongs in order to normalized them. The resulting normalized read counts for each taxon represented a measure of the relative abundance of the various taxa identified in that sample. The sum of the taxa relative abundance per sample is $100 \%$. Differences in microbiota composition were determined using paired t-test or Wilcoxon signed-rank test, following by Shapiro-Wilk test for normality and inspected visually by a histogram. The statistical analyses were performed using SPSS v.22.0. Bonferroni correction for multiple comparisons was applied accordingly. The variation in the data was visualized with principal component analysis (PCA) and done in Canoco 5.0.4 [20]. Through all study we applied four comparisons: (i) Fresh+QIA vs. O24h + QIA, (ii) Fresh + QIA vs. O7d + QIA, (iii) O24h + QIA vs. O7d + QIA and (iv) O24h + QIA vs. O24h + PF.

\section{Bacterial genomic DNA}

In order to confirm observed results from sequencing analysis, we quantified three bacterial groups: Bacteroides spp., Bifidobacterium spp. and Clostridium cluster IV belonging to the three major phyla Bacteroidetes, Actinobacteria and Firmicutes, respectively. Standard for the absolute quantification of these three genera was obtained using genomic DNA of Bacteroides fragilis (ATCC 10584) and Bifidobacterium adolescentis (ATCC 15703) grown at the Department of Medical Microbiology of Radboudumc (Nijmegen, NL) as well as Clostridium leptum (ATCC 753) provided by Deutsche Sammlung von Mikroorganismen und Zellkulturen GmbH (DSMZ; Braunschweig, DE).

In order to detect and quantify Bacteroides spp., Bifidobacterium spp., and Clostridium cluster IV, the group-specific primers based on $16 \mathrm{~S}$ rDNA sequences and probes were used. The probes, primers, and expected amplicon sizes for PCR are summarized in Table 1.

\section{Construction of standard curves for 16S rRNA gene copy number determination}

In order to have an adequate number of DNA fragments for downstream analysis, conventional PCR for the amplification of the 16S rRNA genes was carried out on a genomic DNA of bacterial strains described above. The reaction was performed using the universal bacterial 
Table 1 Primers and probes used to carry out real time PCR quantification of Bacteroides spp., Bifidobacterium spp. and Clostridium cluster IV

\begin{tabular}{|c|c|c|c|c|c|}
\hline Target & Name & Sequence & Amplicon Length & Concentration nM & Ref. \\
\hline \multirow[t]{3}{*}{ Clostridium cluster IV } & sg-Clep-F & GCA CAA GCA GTG GAG T & 239 & 400 & [29] \\
\hline & sg-Clep-R & CTT CCT CCG TTT TGT CAA & & 400 & \\
\hline & Clep-Pa & (FAM)-AGG GTT GCG CTC GTT-(TAMRA) & & 200 & \\
\hline \multirow[t]{3}{*}{ Bifidobacterium spp. } & F-bifido & CGCGTCYGGTGTGAAAG & 244 & 300 & [30] \\
\hline & R-bifido & CCCCACATCCAGCATCCA & & 300 & \\
\hline & MGB-bifido & (FAM)-AACAGGATTAGATACCC-(MGB) & & 200 & \\
\hline \multirow[t]{3}{*}{ Bacteroides spp. } & AllBac296f & GAG AGG AAG GTC CCC CAC & 106 & 400 & [31] \\
\hline & AllBac412r & CGC TAC TTG GCT GGT TCA G & & 400 & \\
\hline & AllBac375Bhqr & (FAM)-CCA TTG ACC AAT ATT CCT CAC TGC TGC CT-(TAMRA) & & 200 & \\
\hline
\end{tabular}

Target Selected species (spp.) tested with qPCR, Name Name of primers and probes used to amplify Target, Sequence primers/probes sequence, Amplicon length the PCR product size of the Target in base pars (bp), Concentration $n M$ concentration of the primers/probes needed to perform experiment, $n M$ nanomolar, Ref. references where the method is described

primers (i) for Bacteroides spp. and Clostridium cluster IV 27F (5'-AGAGTTTGATCCTGGCTCAG-3') and 149 2R (5'-CGGCTACCTTGTTACGAC-3') and (ii) for Bifidobacterium spp. 388F (5'-ACTCCTACGGGAGG CAGCAG-3') and 1492R. The PCR mixture $(50 \mu \mathrm{L})$ was composed of 10× PCR buffer II (Applied Biosystems, Foster City, California, USA), $2.5 \mathrm{mM} \mathrm{MgCl}_{2}$, each dNTP (deoxynucleoside triphosphate) at a concentration of $2.5 \mathrm{mM}$, each primer at a concentration of $50 \mu \mathrm{M}$, $10-100$ ng genomic DNA and 5 units $/ \mu \mathrm{L}$ of Taq DNA polymerase (TAKARA Bio Inc., Kusatsu, Shiga, JPN). The PCR was carried out on an iCycler thermal cycler (Bio-Rad, Hercules, California, USA) under the following conditions: $94{ }^{\circ} \mathrm{C}$ for $5 \mathrm{~min}, 35$ cycles of $94{ }^{\circ} \mathrm{C}$ for $30 \mathrm{~s}, 52{ }^{\circ} \mathrm{C}$ for $40 \mathrm{~s}$, and $72{ }^{\circ} \mathrm{C}$ for $90 \mathrm{~s}$; and finally $72{ }^{\circ} \mathrm{C}$ for $7 \mathrm{~min}$. The PCR products were purified using the Mini Elute PCR Purification kit (QIAGEN, Venlo, NL) according to the manufacturer's instructions and were subjected after purification to a 1\% agarose gel electrophoresis containing GelRed and visualized for being (approximately) 1465 bp in size. DNA quantity and quality was measured via NanoDrop 2000 spectrophotometer (Thermo Scientific, Breda, NL).

\section{Real-time PCR assay}

The purified PCR products of aforementioned bacterial strains were used as standard-samples in real-time PCR (qPCR) in order to calculate the $16 \mathrm{~S}$ gene copy number. qPCR and Next Generation Sequencing (NGS) appear as robust and efficient tools for the detection and/or quantification of a wide range of bacterial DNA. Therefore, GPCR was used to confirm observed results from the sequencing analysis. The assay was performed with an ABI PRISM 7900HT sequence detection system (Applied Biosystems, Foster City, California, USA) in a volume of $10 \mu \mathrm{L}$ with TaqMan ${ }^{\circledR}$ Fast Universal PCR Mastermix (Applied Biosystems, Foster City, California, USA) with the addition of each primer and probe at specific concentrations described in Table 1. The program cycle conditions were: $50{ }^{\circ} \mathrm{C}$ for $2 \mathrm{~min}$ and $95{ }^{\circ} \mathrm{C}$ for $10 \mathrm{~min}$, followed by (i) for Bacteroides spp. 40 cycles of $95{ }^{\circ} \mathrm{C}$ for $30 \mathrm{~s}, 60{ }^{\circ} \mathrm{C}$ for $1 \mathrm{~min}$ and $72{ }^{\circ} \mathrm{C}$ for $1 \mathrm{~min}$ (ii) for Bifidobacterium spp. 40 cycles of $95^{\circ} \mathrm{C}$ for $15 \mathrm{~s}$, $60{ }^{\circ} \mathrm{C}$ for $1 \mathrm{~min}$ and $72{ }^{\circ} \mathrm{C}$ for $1 \mathrm{~min}$ and (iii) for Clostridium cluster IV 40 cycles of $95{ }^{\circ} \mathrm{C}$ for $30 \mathrm{~s}, 53{ }^{\circ} \mathrm{C}$ for $45 \mathrm{~s}$, and $60{ }^{\circ} \mathrm{C}$ for $1 \mathrm{~min}$. The $16 \mathrm{~S}$ rRNA gene copy number was calculated using the equation:

\section{copy number $/ \boldsymbol{\mu L}=(\mathrm{C} / \mathrm{X}) \times \mathbf{x} 0.912 \times 1012$}

where C: DNA concentration measured $(n g / \mu \mathrm{L})$ and $\mathrm{X}$ : PCR fragment length (bp/copy) [21].

\section{Calculation of log $16 \mathrm{~S}$ gene copy number per gram of feces}

In order to quantify aforementioned bacterial DNA, we calculated the $\log 16 \mathrm{~S}$ gene copy number per gram of faces. By taking into account the threshold cycle $\left(C_{T}\right)$ values obtained by a known concentration of $16 \mathrm{~S}$ rRNA, the intercept, the slope, the DNA extraction volume, the sample dilution factor, the fecal sample weight and the number of $\mu \mathrm{L}$ per well.

\section{Results}

In the present study, (i) we compared two collection and storage methods (Fresh; OMNIgene.GUT) and (ii) we accounted for two common DNA extraction methods (QIA; PF) experimental design can be found in Additional file 1: Figure S1 and Additional file 2: Figure S2, respectively.

\section{DNA concentration and purity}

OMNIgene.GUT kit (O24h; mean concentration = $267.22 \mathrm{ng} / \mathrm{uL} ; N=14$ ) had a lower DNA concentration than Fresh (mean concentration $=304.60 \mathrm{ng} / \mathrm{uL}$; 
$\mathrm{N}=14$ ), although those results were not statistically significant (paired t-test; $P>0.05$ ). The DNA concentration of the samples collected with the OMNIgene.GUT kit after 7 days of storage (at room temperature; O7d) had lower values (mean concentration $=223.27 \mathrm{ng} / \mathrm{uL} ; \mathrm{N}=14 ; P>0.05$ ) compared to O24h (Table 2). Furthermore, O7d and Fresh also did not show differences, $(P>0.05)$. DNA purity of the Fresh, O24h and O7d showed similar optimal values for the ratio of absorbance and those values did not show statistical differences $(P>0.05)$ (Table 2).

Comparison of the QIA and PF DNA-isolation methods showed differences where PF resulted in approximately seven times lower DNA concentration $(\mathrm{PF}=41.31 \mathrm{ng} / \mathrm{uL}$; $\mathrm{QIA}=267.22 \mathrm{ng} / \mathrm{uL} ; P<0.001)$ and about two times lower DNA purity indicated by $260 \mathrm{~nm} / 230 \mathrm{~nm}$ ratio $(\mathrm{PF}=1.02$; QIA $=1.66 ; P<0.001$ ) (Table 2). This suggests that the QIA method is superior with regard to both DNA concentration and purity.

\section{Illumina sequencing}

16S rRNA gene (16S) sequencing was performed for 56 samples (Additional file 2: Figure S2) and 5 positive controls. After the quality control step it yielded $3,532,503$ reads associated to 78,470 OTUs and 49,388 observed bacterial species determined by $16 \mathrm{~S}$ sequences having 97\% similarity. The total read counts per sample were compared between three different collection methods (Fresh, O24h, O7d) and between two different DNA extraction methods to investigate if sequence depth differ between them. No statistically significant differences between all tested methods were found (Additional file 3: Table S1-S2).

\section{Microbiome composition of the fecal samples}

The gut microbiota composition of the participants was mainly characterized by the following phyla: Actinobacteria, Bacteroidetes, Firmicutes, Proteobacteria, and Cyanobacteria (data not shown). We tested whether the microbiome composition of the fecal samples differed among collection/storage methods or DNA extraction kits.

\section{Alpha diversity}

The impact of the different conditions on the alpha bacterial diversity of the fecal samples was assessed based on the Shannon diversity index. DNA extraction using the PF kit yielded significantly lower alpha diversity scores (within sample variation) compared to the QIA kit (Wilcoxon signed-rank test; $P>$ 0.001 ), whereas no differences were found between collection methods (O24h, O7d, Fresh) (Fig. 1).

\section{Phylum relative abundance}

Samples collected with OMNIgene.GUT (O24h \& O7d) showed a trend towards higher phylum relative abundance of Bacteroidetes, Cyanobacteria, Proteobacteria and lower of Firmicutes and Actinobacteria compared to the Fresh method (Fig. 2 and Table 3). Bacteroidetes, Actinobacteria and Cyanobacteria are significantly different (Wilcoxon signed-ranks test; $P<0.05$; Bonferroni-adjusted) in O24h compared to Fresh. However, the Bonferroni-adjusted $p$-value did not reach statistical significance for O7d compared to Fresh, except for Cyanobacteria $(p=0.045)$. Moreover, phylum relative abundance did not significantly differ across different storage durations used for the OMNIgene.GUT kit (O24h vs. O7d) (Fig. 2 and Table 3).

Relative abundance of the all bacterial phyla (Firmicutes, Bacteroidetes, Actinobacteria, Cyanobacteria and Proteobacteria) differed among DNA extraction methods (Figs. 2 \& 3). The most abundant phylum among the O24h samples extracted with QIA was Firmicutes with the average of $72 \%$ (Fig. 3a). However, this was not observed in the case of the samples extracted with PF, where Firmicutes average was $47 \%$ (Fig. 3b). Compared

Table 2 DNA quantification and purification values. Mean values with standard deviation (SD) for DNA concentration and purity of fecal samples collected and stored by three different collection/storage methods (Fresh, O24h, O7d) and extracted using two different procedures (PF, QIA)

\begin{tabular}{llll}
\hline & \multicolumn{2}{l}{} & \\
\cline { 2 - 4 } & DNAnoDrop measurements (mean \pm SD) & $260 \mathrm{~nm} / 230 \mathrm{~nm}$ ratio \\
\hline Fresh + QIA & $304.60 \pm 106.35$ & $260 \mathrm{~nm} / 280 \mathrm{~nm}$ ratio & $1.67 \pm 0.20$ \\
O24h + QIA & $267.22 \pm 98.38^{\mathrm{a}}$ & $1.86 \pm 0.02$ & $1.66 \pm 0.16^{\mathrm{b}}$ \\
O7d + QIA & $223.27 \pm 100.03$ & $1.88 \pm 0.01$ & $1.60 \pm 0.19$ \\
O24h + PF & $41.31 \pm 32.52^{\mathrm{a}}$ & $1.88 \pm 0.02$ & $1.02 \pm 0.50^{\mathrm{b}}$ \\
\hline
\end{tabular}

The ratios of absorbance at $260 \mathrm{~nm} / 280 \mathrm{~nm}$ and $260 \mathrm{~nm} / 230 \mathrm{~nm}$ are used to assess the purity of DNA. A ratio of $\sim 1.8$ is generally accepted as "pure" for DNA. If the ratio is appreciable lower, it may indicate the presence of contaminants (e.g. proteins, phenols or carbohydrates) (13, 14). ${ }^{a}$ Is the comparison of DNA concentration (column labeled DNA concentration, $\mathrm{ng} / \mu \mathrm{L}$ ) and ${ }^{\mathrm{b}}$ of DNA purity (column labeled $260 \mathrm{~nm} / 230 \mathrm{~nm}$ ratio) between QIA and PF DNA extraction methods (Bonferroni-adjusted paired sample t-test with $P<0.001$ for all tests) 


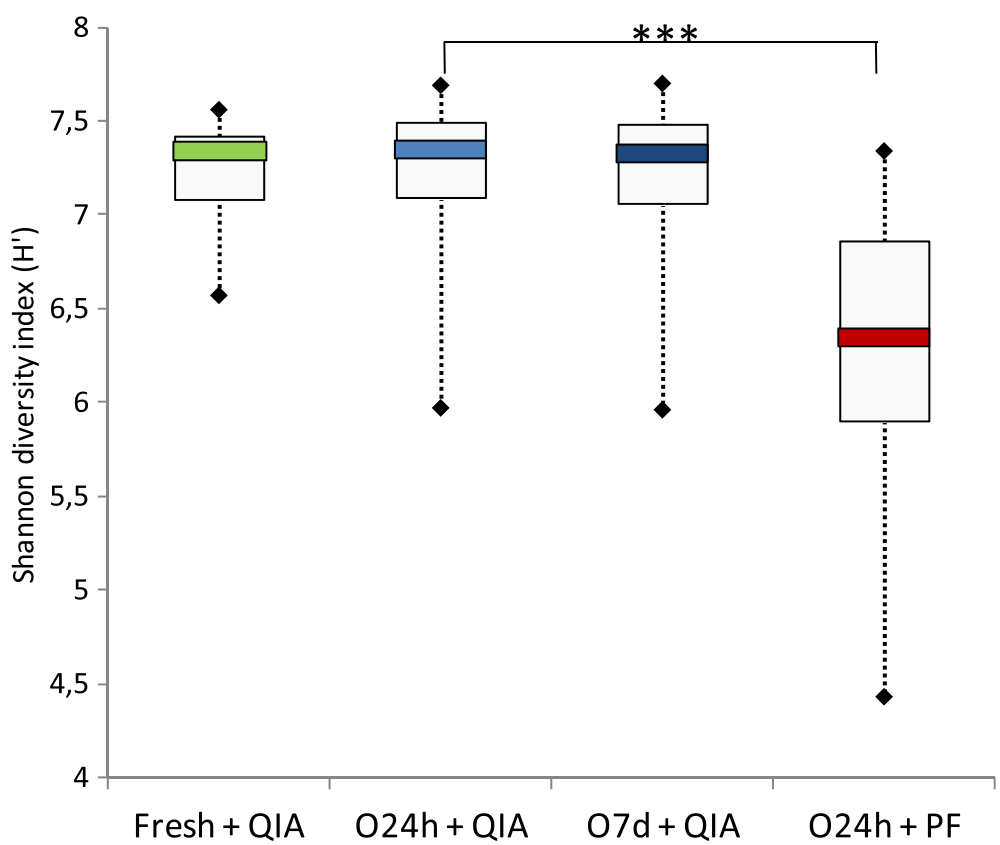

Fig. 1 Shannon diversity index of fecal samples collected/stored with three different collection and storage methods (Fresh, O24h, O7d) and extracted using two different procedures (PF, QIA) $\left(^{* * *} P>0.001\right)$; results determined by sequencing analysis

to QIA, PF showed significantly higher abundance of Bacteroidetes (Bonferroni-adjusted Wilcoxon signed-ranks test; $P<0.01)$, Cyanobacteria $(P<0.05)$ and Proteobacteria $(P<0.01)$, and lower abundance of Firmicutes $(P<0.01)$ and Actinobacteria $(P<0.01)$.

\section{Microbiome ordination}

Principal Component Analysis (PCA) shows that samples belonging to the same individual strongly clustered for 12 out of 14 individuals, across the different collection and storage methods (Fig. 4a). Additionally,

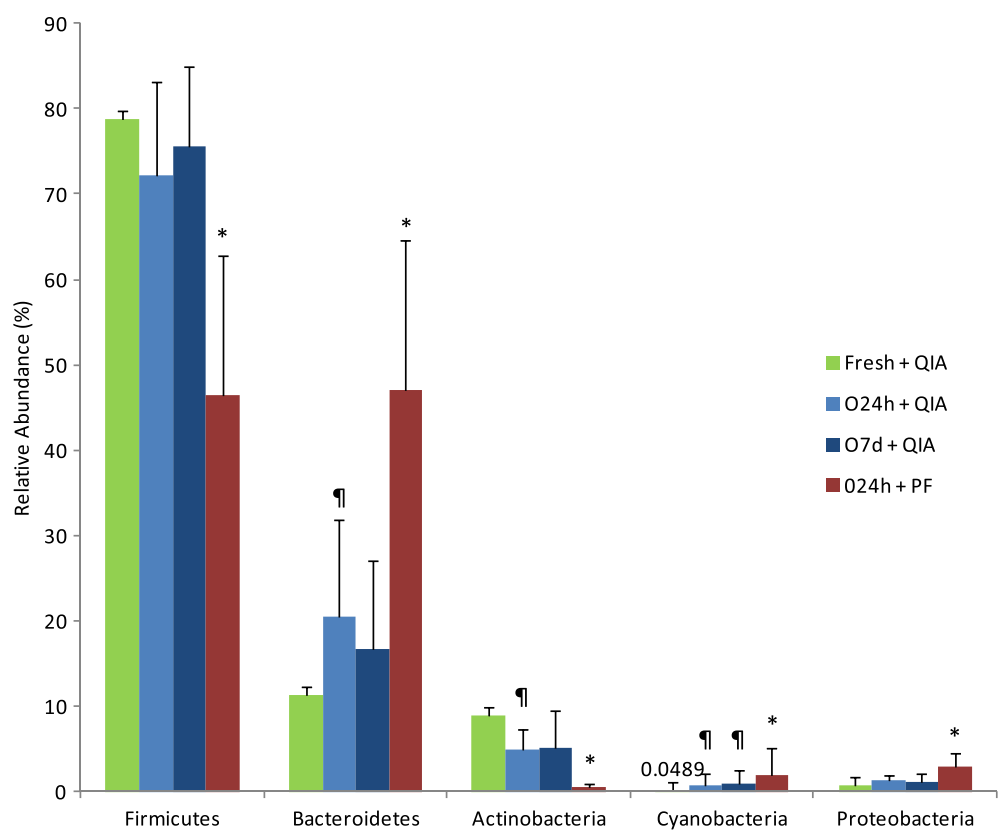

Fig. 2 Relative abundance of bacterial taxa at the phylum level in fecal samples collected/stored with three different methods (Fresh, O24h, O7d) and extracted using two different procedures (PF, QIA); results determine by sequencing analysis. Statistical comparisons were performed based on the paired sample t-test. * red bar statistically different from light-blue bar $(P<0.05)$; 9 blue bar statistically different from green bar $(P<0.05)$ 
Table 3 Phylum relative abundance of each samples extracted using two different DNA extraction methods and collected with three different procedures; results determined by sequencing analysis

\begin{tabular}{llllll}
\hline \multirow{2}{*}{ Collection + DNA extraction methods } & \multicolumn{4}{l}{ Mean of phyla relative abundance $(\%) \pm$ standard error of the mean } \\
\cline { 2 - 6 } & Firmicutes & Bacteroidetes & Actinobacteria & Cyanobacteria & Proteobacteria \\
\hline Fresh + QIA & $77.82 \pm 7.22$ & $11.25 \pm 6.23$ & $8.90 \pm 4.28$ & $0.05 \pm 0.09$ & $0.72 \pm 0.46$ \\
O24h + QIA & $72.10 \pm 11.09$ & $20.52 \pm 11.39$ & $4.89 \pm 2.38$ & $0.74 \pm 1.32$ & $1.26 \pm 0.76$ \\
O7d + QIA & $75.52 \pm 9.43$ & $16.63 \pm 10.46$ & $5.20 \pm 4.26$ & $0.90 \pm 1.67$ & $1.20 \pm 0.83$ \\
O24h + PF & $46.52 \pm 16.21$ & $46.94 \pm 17.71$ & $0.54 \pm 0.42$ & $1.95 \pm 3.12$ & $2.94 \pm 1.49$ \\
\hline
\end{tabular}

First column refers to the tested collection/storage and DNA extraction methods in the paper. The other columns represent relative abundance of the phyla that were investigated

collection and storage methods grouped closely together, while the two different DNA extraction methods appeared to cluster less well (Fig. 4b).

\section{Real-time PCR assay}

Bacteroides spp., Bifidobacterium spp. and Clostridium cluster IV were selected to confirm our results observed

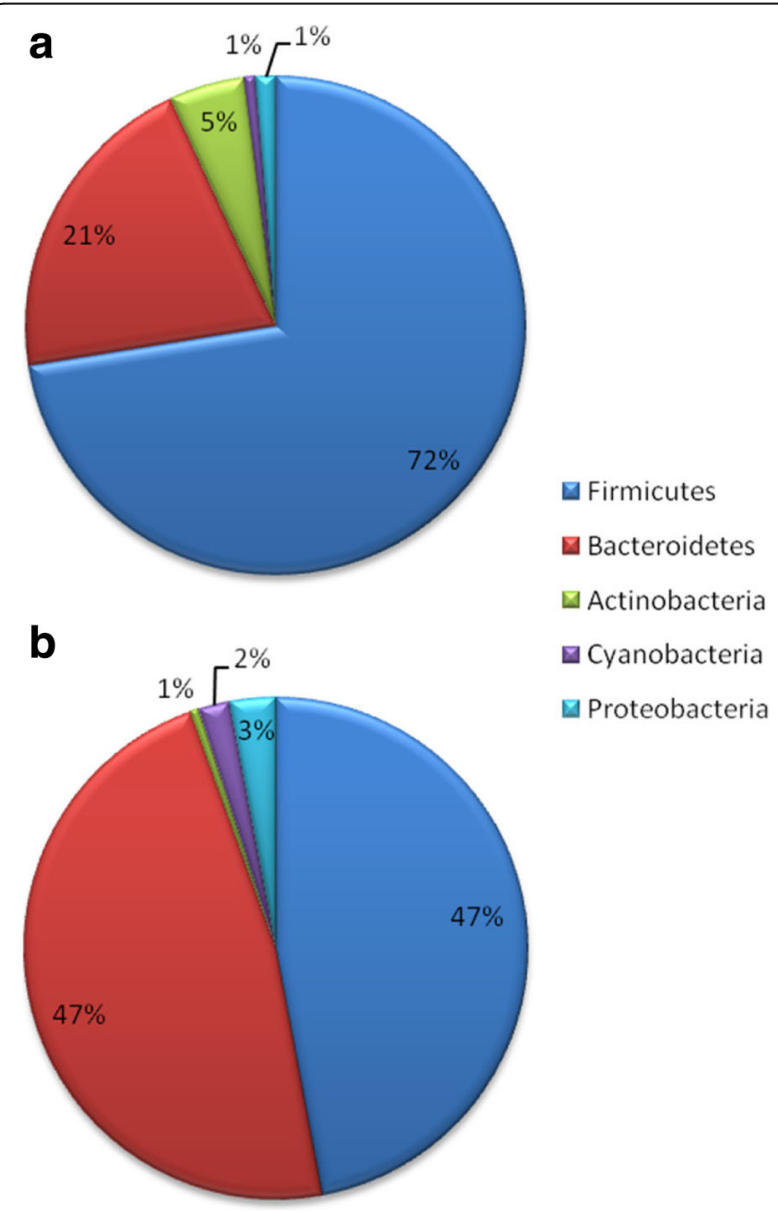

Fig. 3 Relative abundance of bacterial phyla of O24h samples treated with QIA (a) and PF (b) DNA extraction kits; results determined by sequencing analysis. All phyla showed statistically significant differences between two DNA extraction methods (Bonferroni-adjusted Wilcoxon signed-rank test; $P<0.05$ for all tests) by the Illumina MiSeq sequencing. There were no differences in bacterial amounts among the collection/ storage conditions. However, the quantification of Bacteroides (paired t-test; $P<0.001$ ), Bifidobacterium (paired t-test; $P<0.001$ ) and Clostridium cluster IV (paired t-test; $P<0.001$ ) groups revealed significantly lower amounts in samples extracted by the $\mathrm{PF}$ compared to QIA, as shown in Fig. 5.

\section{Discussion}

In this study, based on 14 fecal samples collected from healthy individuals ( 7 males, 7 females) we examined the performance of the OMNIgene.GUT kit in terms of bacterial DNA quantity and quality as an alternative to the collection of fresh human feces accounting for the impact of two different bacterial DNA extraction methods. To summarize our results, as a primary step we showed that read counts did not differ among all four comparisons (between collection and between DNA extraction methods). Furthermore, DNA concentration, purity and Shannon diversity index did not show differences between Fresh and OMNIgene.GUT kit.

The phylum relative abundance showed statistically significant differences in Bacteroidetes, Actinobacteria and Cyanobacteria between Fresh and O24h, but not between Fresh and O7d nor between O24h and O7d. This very specific effect could be explained by our limited sample size $(N=14)$ in combination with the number of tests performed (15 tests). When we increased the taxonomic resolution for subsequent analysis, this difference disappeared. The PCA analysis (Fig. 4) showed no differences between Fresh, O24h and O7d in terms of general microbial composition at the genus level. Furthermore when we validated our results, using $\mathrm{qPCR}$ of bacterial species representative of three tested phyla (see methods section) we confirmed that there were no differences (here at the species level) between the Fresh, O24h and O7d storage methods.

We determined the reliability of the OMNIgene.GUT kit accounting for two commonly used DNA extraction methods, which showed significant differences in terms of DNA quantity, quality, bacterial diversity and relative abundance. Revealing that the choice of DNA extraction 


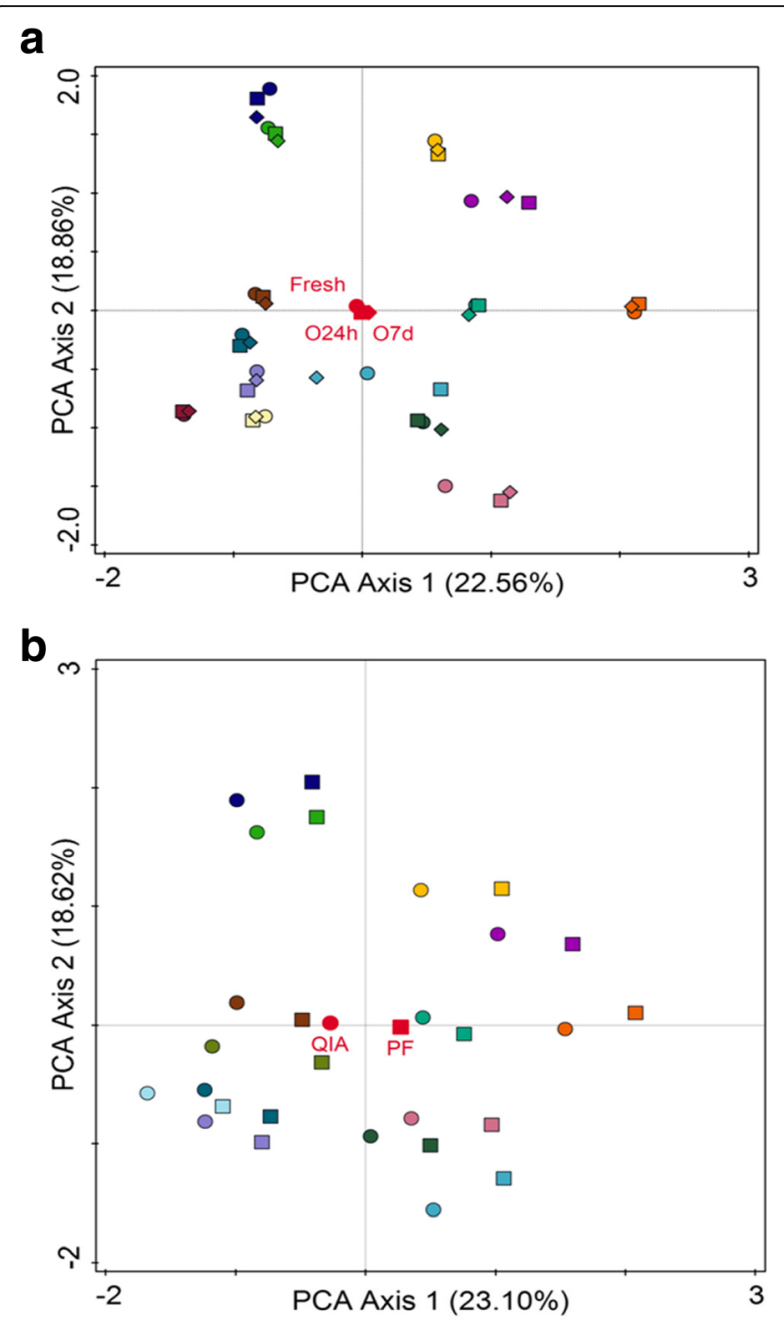

Fig. 4 PCA (Principal Component Analysis) plots of bacterial genera relative abundance of 14 individual faecal samples clustered regarding collection and storage methods (Fresh, O24h, O7d) (a) or DNA extraction methods (PF, QIA) (b). The first two components explained $22.56 \%$ and $18.86 \%$ of the variance, respectively (A) and $23.10 \%$ and $18.62 \%$ of the variance, respectively (b). Faecal collection methods are represented by circle $(\bullet)$ for Fresh, square (- for O24h, and triangle $(\boldsymbol{\Lambda})$ for O7d (a). DNA extraction methods are represented by circle $(\bullet)$ for QIA, and square $(\mathbf{\bullet})$ for $\mathrm{PF}(\mathbf{b})$; results determined by sequencing analysis

method influences the gut microbiome profile. We discovered that by combining the OMNIgene.GUT kit and QIA extraction method we maximized the information content. However, we do not have objective reason why one method would work less efficient from the other.

Studies on the overall relative abundance and diversity of bacterial communities in fecal samples stored at room temperature have shown controversial results. Gorzelak et al. (2015) reported alterations in terms of bacterial taxa abundance and diversity in fecal samples stored at room temperature. These alterations might result from lack of nucleic acid stabilizer [22]. Additionally, the

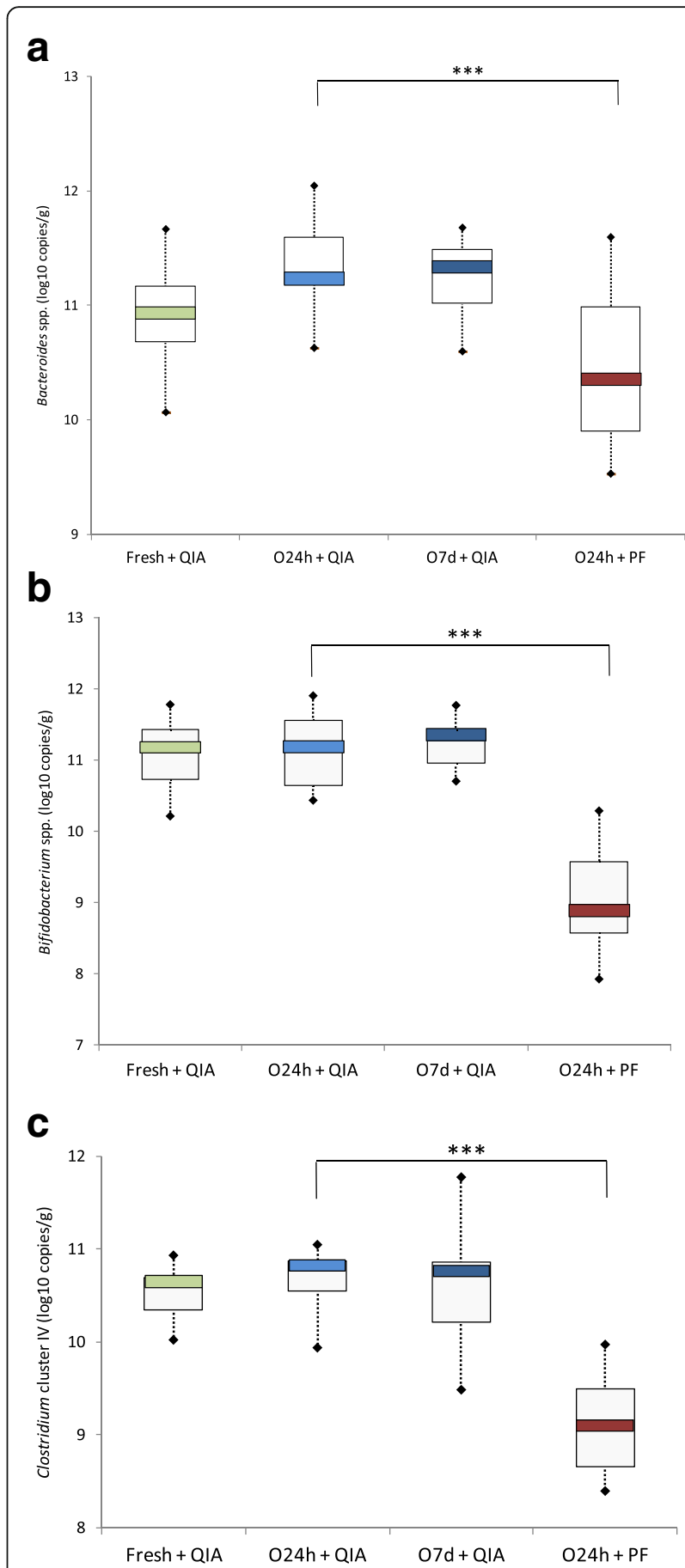

Fig. 5 Log base 10 of gene copy number per gram of feces of Bacteroides spp. a, Bifidobacterium spp. b and Clostridium cluster IV (c) quantified by real-time PCR for the different collection and DNA extraction kits $\left({ }^{* *} P<0.001\right)$

homogenization procedure showed an effect on the variability in gut microbiome data [22]. Of note, the OMNIgene.GUT kit was not included in those studies; this kit includes a homogenization step at the point of collection and contains microbial growth stabilizer. 
The two other studies, Tedjo et al. (2015) and Dominianni et al. (2014) [23, 24], revealed no significant changes in microbiome structure and relative abundance. The OMNIgene.GUT kit was not included in those studies. Research by Tedjo et al. (2015) suggested that storage up to $24 \mathrm{~h}$ at room temperature did not affect the fecal microbial composition compared to direct freezing $\left(-80{ }^{\circ} \mathrm{C}\right)$ of samples from healthy individuals $(N=10)$ and people with gastrointestinal disorders $(N=$ 22). Importantly, they recommended applying a single storage method within a study to prevent potential bias in the results. Dominianni et al. (2015) did not find significant differences in overall microbial structure and relative abundance of storage at room temperature for 3 days compared to samples of healthy individuals $(N=$ 3) immediately frozen at $-80{ }^{\circ} \mathrm{C}$. However, they acknowledged that a larger cohort could show variation.

As summarized in Table 4, several studies have investigated the impact of room temperature storage on microbiome composition, including the OMNIgene•GUT kit. Choo et al. (2015) reported no significant differences in Shannon diversity index (in agreement with our results), an increase of Proteobacteria relative abundance (we observed no changes) and no significant differences of
Actinobacteria, Firmicutes and Bacteroidetes taxa for OMNIgene.GUT samples compared to frozen control $\left(-80{ }^{\circ} \mathrm{C}\right)$. We observed significant differences in relative abundance of these two phyla, lower in Actinobacteria and higher in Bacteroidetes for O24h, and no differences for O7d when compared to Fresh. Choo et al. results are partially in line with our findings and this could be due to using different control groups (Choo et al. $-80{ }^{\circ} \mathrm{C}$ and our $4{ }^{\circ} \mathrm{C}$ ). However, Choo et al. showed that different sample storage conditions $\left(-80{ }^{\circ} \mathrm{C}\right.$ vs $\left.4{ }^{\circ} \mathrm{C}\right)$ do not seem to have a significant impact on the microbial composition [25]. Another way to explain the abundance differences observed between our and Choo et al. results may be the use of different DNA extraction methods, which, as we could observe in the present study, had a significant impact on microbiome composition. Additionally, their results were based on a single individual while we investigated 14 participants.

Song et al. (2016) showed that storage of fecal samples $(N=15)$ using the OMNIgene.GUT kit for up to 8 weeks did not affect fecal microbial community structure. They recommend this kit to be used for microbiome studies including long-term studies, which is in concordance with our findings.

Table 4 Comparison of the microbiome storage studies carried out since 2014

\begin{tabular}{|c|c|c|c|c|c|c|}
\hline $\begin{array}{l}\text { Number of } \\
\text { individuals }\end{array}$ & $\begin{array}{l}\text { Time of } \\
\text { RT storage }\end{array}$ & Design & $\begin{array}{l}\text { DNA extraction } \\
\text { method }\end{array}$ & Techniques & Conclusion & Ref. \\
\hline 1 & $72 \mathrm{~h}$ & $\begin{array}{l}\text { Comparison of OMNIgene.GUT/ } \\
\text { RNA later/ Tris-EDTA buffer } \\
\text { storage methods }\end{array}$ & $\begin{array}{l}\text { MoBio Powelyser } \\
\text { Powersoil DNA } \\
\text { Isolation Kit }\end{array}$ & $\begin{array}{l}\text { Illumina MiSeq 16S } \\
\text { rRNA }\end{array}$ & $\begin{array}{l}\text { Least alteration from } \\
\text { OMNlgene.GUT }\end{array}$ & {$[25]$} \\
\hline 3 & 3 days & $\begin{array}{l}\text { Comparison of RNAlater } \\
\text { storage at RT for } 3 \text { days } \\
\text { vs. storage at }-80{ }^{\circ} \mathrm{C}\end{array}$ & $\begin{array}{l}\text { MO BIO Powelyser } \\
\text { Powersoil DNA } \\
\text { isolation kit }\end{array}$ & $\begin{array}{l}454 \text { sequencing of } \\
16 S \text { rRNA }\end{array}$ & $\begin{array}{l}\text { RNAlater tend to show } \\
\text { lower diversity and } \\
\text { purity }\end{array}$ & [24] \\
\hline $\begin{array}{l}18 \text { (IBS-IBD } \\
\text { patients + } \\
\text { controls) }\end{array}$ & $24 \mathrm{~h}$ & $\begin{array}{l}\text { Comparison between storage } \\
\text { at RT for } 24 \mathrm{~h} / \text { storage at }+4{ }^{\circ} \mathrm{C} \\
\text { for } 24 \mathrm{~h} / \text { storage at }-20{ }^{\circ} \mathrm{C} \text { for } \\
\text { one week vs. storage at }-80{ }^{\circ} \mathrm{C}\end{array}$ & $\begin{array}{l}\text { PSP lysis buffer+ } \\
\text { beat-beating+ PSP } \\
\text { Spin stool kit }\end{array}$ & $\begin{array}{l}454 \text { sequencing of } \\
16 S \text { RNA + qPCR on } \\
\text { Methanobrevibacter } \\
\text { smithii }\end{array}$ & $\begin{array}{l}\text { No significant differences } \\
\text { between the storage at RT } \\
\text { for } 24 \mathrm{~h} \text {, storage at } 4{ }^{\circ} \mathrm{C} \text { for } \\
24 \mathrm{~h} \text { and storage at }-20^{\circ} \mathrm{C} \\
\text { for one week. }\end{array}$ & [23] \\
\hline 4 & 15 or $30 \mathrm{~min}$ & $\begin{array}{l}\text { Comparison between storage } \\
\text { at RT for } 15 \text { min vs. } 30 \text { min vs. } \\
\text { no buffer }\end{array}$ & $\begin{array}{l}\text { Qiagen stool Mini } \\
\text { kit+ Bead-beating }\end{array}$ & qPCR & $\begin{array}{l}\text { Fecal samples should be } \\
\text { frozen within } 15 \text { min } \\
\text { counting from collection. }\end{array}$ & {$[22]$} \\
\hline $\begin{array}{l}41 \text { (19 elderly } \\
+22 \text { infants) }\end{array}$ & 7 or 14 days & $\begin{array}{l}\text { Storage at RT within } \\
\text { OMNIgene.GUT kit for } 7 \\
\text { or } 14 \text { days vs. fresh samples }\end{array}$ & RBB & $\begin{array}{l}\text { Ilumina MiSeq + } \\
\text { PicoGreen }\end{array}$ & $\begin{array}{l}\text { OMNlgene.GUT kit did not } \\
\text { significantly impact } \\
\text { microbiota composition and } \\
\text { diversity in elderly datasets } \\
\text { after } 7 \mathrm{~d} \text { of storage. It can be } \\
\text { used instead of fresh method. }\end{array}$ & [13] \\
\hline 14 & $24 \mathrm{~h}$ and 7 days & $\begin{array}{l}\text { Comparison of storage at RT } \\
\text { within OMNlgene.GUT for } \\
24 \mathrm{~h} \text { or } 7 \text { days vs freezing }+ \\
\text { comparison of two DNA } \\
\text { extraction method }\end{array}$ & $\begin{array}{l}\text { MO BIO Power } \\
\text { Fecal DNA Isolation } \\
\text { Kit vs. Qiagen QIAmp } \\
\text { DNA Stool Mini kit+ } \\
\text { bead-beating }\end{array}$ & $\begin{array}{l}\text { Illumina MiSeq } \\
16 S \text { RNA + qPCR } \\
\text { on Bacteroides } \\
\text { spp., Bifidobacterium } \\
\text { spp. and Clostriduim } \\
\text { cluster IV }\end{array}$ & $\begin{array}{l}\text { Significant influence of DNA } \\
\text { extraction method + no } \\
\text { influence of storage within } \\
\text { OMNlgene-GUT and between } \\
\text { OMNIgene-GUT vs. Fresh in } \\
\text { terms of microbial diversity } \\
\text { and quantity }\end{array}$ & $\begin{array}{l}\text { Our } \\
\text { study }\end{array}$ \\
\hline
\end{tabular}


We investigated two different DNA extraction methods which yielded different microbial DNA concentrations and help explain the differences in microbiome composition observed between studies. Previous studies $[26,27]$ have also shown differences in terms of microbial diversity and abundance among different bacterial DNA extraction methods. Larsen et al. (2015) showed that the QIAamp DNA Stool Mini Kit (Qiagen, Valencia, CA) performed better than the DNeasy Blood and Tissue Kit (Qiagen, Valencia, CA) in terms of downstream analysis of fish gut microbiota. Peng et al. (2013) demonstrated the impact of 5 commercial DNA extraction methods on gut microbiota analysis. Similar patterns of bacterial communities were found in four out of five commercial kits $(N=1)$; an exception was the MO BIO method (UltraClean ${ }^{\text {ma }}$ Fecal DNA Kit; MO BIO, USA). The MO BIO kit showed lower microbial diversity in the work of Peng [26], which is in concordance with our results on the use of PowerFecal ${ }^{\circ}$ DNA Isolation Kit (MO BIO Laboratories, Inc.). Moreover, changes in the Firmicutes to Bacteroidetes ratio (F:B ratio) have been reported in the literature in patients with irritable bowel syndrome (IBS), obesity, and autism spectrum disorder (ASD) [28], and have been suggested as a potential biomarker. Our results indicate that the DNA extraction method has a strong effect on F:B ratio (PF 1:1 ratio; QIA 3.4:1 ratio) (Fig. 3). Therefore, the DNA extraction method has to be taken into account when comparing microbiome analysis across different sites (as well as a collection, storage, transport and 16S sequencing methods). Based on our results, the QIA method appears to be adequate for microbiome studies, since it showed higher DNA concentration, purity and bacterial diversity.

This study should be seen in the light of several strengths and limitations. The strengths of this study are the ability to compare different collection and storage methods while accounting for two different DNA extraction methods. We showed the results across two complementary techniques: qPCR and Illumina sequencing. The limitation of our study is the sample size. Larger sample sizes would further improve the generalizability of our results, increase statistical power and allow the detection of small differences between collection methods if any occur. We used 16S rRNA gene amplicon as an approach for microbiome analysis. Therefore, further investigations can take into account another common approach, metagenomics, in which bacterial structure and function are revealed based on whole genome sequencing.

\section{Conclusion}

In this study, we highlighted the potential of using the OMNIgene.GUT kit for collection and storage at ambient temperature, which is convenient for studies aiming to collect large samples by giving participants the possibility to send samples by post. Our results underscore the importance of the choice of a DNA extraction method for the proper human gut microbial representation.

\section{Additional files}

\begin{abstract}
Additional file 1: Figure S1. Experimental design. Faecal samples were collected from 14 healthy participants in triplicates. Afterwards, the samples were stored (i) at $4{ }^{\circ} \mathrm{C}$ straight after collection and processed within $24 \mathrm{~h}$ (Fresh), (ii) at RT using the OMNlgene.GUT kit for $24 \mathrm{~h}$ (O24h) or (iii) for seven days (O7d) and then processed. (DOCX $94 \mathrm{~kb}$ )

Additional file 2: Figure S2. Experimental design. DNA from faecal samples was extracted using QIA and PF methods. DNA from Fresh, O24h and O7d samples was extracted using QIA method; DNA from the O24h samples was also extracted using PF method. (DOCX 76 kb)

Additional file 3: Table S1. Read counts information per samples collected and stored by three different collection/storage methods (Fresh, O24h, O7d) and extracted using two different procedures (PF, QIA). Table S2. Comparison of the read counts per samples between three different collection/storage methods (Fresh, O24h, O7d) and two different DNA extraction procedures (PF, QIA). Paired sample t-test showed no statistical differences between any of the groups in terms of read count. (XLSX $15 \mathrm{~kb}$ )
\end{abstract}

\section{Abbreviations \\ 16S: 16 rRNA gene; ASD: Autism spectrum disorder; bp: base pair; dNTP: Deoxynucleoside triphosphate; DSMZ: Deutsche Sammlung von Mikroorganismen und Zellkulturen; IBS: Irritable bowel syndrome; mM: millimolar; ng: nanogram; NGS: Next generation sequencing; OTU: Operational taxonomy unit; PCA: Principal component analysis; PCR: Polymerase chain reaction; PEAR: Paired-End reAd mergeR; PF: PowerFecal ${ }^{\oplus}$ DNA Isolation Kit; pM: picomolar; PyNAST: Python Nearest Alignment Space Termination; QIA: QIAamp DNA Mini Kit; \\ QIIME: Quantitative Insights into Microbial Ecology; qPCR: real-time PCR; rDNA: ribosomal DNA; RDP: Ribosomal database project; rRNA: ribosomal RNA; RT: Room temperature; spp.: species plural; $\mu \mathrm{L}$ : microlitre; $\mu \mathrm{M}$ : micromolar}

\section{Acknowledgments}

The authors acknowledge the assistance of Arjan de Jong (Department of Medical Microbiology at Radboudumc, NL).

\section{Funding}

This project has received funding from the European Union's Horizon 2020 research and innovation programme under the Marie Sklodowska-Curie grant agreement No 643051. The founding body had no role in the manuscript.

\section{Availability of data and materials}

The dataset is available from the corresponding author and can be obtained on reasonable request.

\section{Authors' contributions}

AAV designed, supervised and approved the study. RG and SvdM performed the sampling. RG, SvdM, JB, SL and IvS performed laboratory analyses. RG, JWS and SvdM analyzed the data. BF, HT and CB gave crucial input in study design, data analysis and interpretation of the results. RG and JWS wrote the paper with input from all co-authors. All co-authors reviewed and approved the manuscript prior to submission.

\section{Ethics approval and consent to participate}

The need for ethics approval was waived by the local medical ethics committee from Radboudumc and is deemed unnecessary according to local guidelines. This study investigated the performance of feces collection kits and bacterial DNA isolation kits. It did not pertain with any (clinical/ biological) investigation of any human tissue at any level. 
Verbal and written consent was obtained from all participants. Ethics Approval was not required by the local medical ethics committee from Radboudumc as it was deemed unnecessary according to committee's requirements.

\section{Consent for publication}

Not applicable.

\section{Competing interests}

The authors declare that they have no competing interests.

\section{Publisher's Note}

Springer Nature remains neutral with regard to jurisdictional claims in published maps and institutional affiliations.

\section{Author details}

${ }^{1}$ Department of Psychiatry, Radboudumc, Donders Institute for Brain, Cognition and Behaviour, P.O. Box 9101 HB, Nijmegen, The Netherlands. ${ }^{2}$ UMR 454 MEDIS UCA-INRA, Université Clermont Auvergne, F-63000 Clermont-Ferrand, France. ${ }^{3}$ Department of Human Genetics, Radboudumc, Donders Institute for Brain, Cognition and Behaviour, P.O. Box 9101 HB, Nijmegen, The Netherlands. ${ }^{4} \mathrm{NIZO}$ Food Research BV, P.O. Box 20, 6710 BA Ede, The Netherlands. 'Laboratory of Microbiology, Wageningen University, Stippeneng 4, 6708 WE Wageningen, The Netherlands. 'Department of Cognitive Neuroscience, Radboudumc, Donders Institute for Brain, Cognition and Behaviour, P.O. Box 9101 HB, Nijmegen, The Netherlands.

\section{Received: 23 February 2018 Accepted: 27 August 2018}

\section{Published online: 06 September 2018}

\section{References}

1. Cryan JF, Dinan TG. Mind-altering microorganisms: the impact of the gut microbiota on brain and behaviour. Nat Rev Neurosci. 2012;13(10):701-12.

2. Flint HJ, Scott KP, Louis P, Duncan SH. The role of the gut microbiota in nutrition and health. Nat Rev Gastroenterol Hepatol. 2012:9(10):577-89.

3. Chow J, Lee SM, Shen Y, Khosravi A, Mazmanian SK. Host-bacterial symbiosis in health and disease. Adv Immunol. 2010;107:243-74.

4. de Vos WM, de Vos EA. Role of the intestinal microbiome in health and disease: from correlation to causation. Nutr Rev. 2012;70(Suppl 1):S45-56.

5. Aarts E, Ederveen THA, Naaijen J, Zwiers MP, Boekhorst J, Timmerman HM, et al. Gut microbiome in ADHD and its relation to neural reward anticipation. PLoS One. 2017;12(9):e0183509.

6. Wang WL, Xu SY, Ren ZG, Tao L, Jiang JW, Zheng SS. Application of metagenomics in the human gut microbiome. World J Gastroenterol. 2015; 21(3):803-14.

7. Scott KP, Antoine JM, Midtvedt T, van Hemert S. Manipulating the gut microbiota to maintain health and treat disease. Microb Ecol Health Dis. 2015:26:25877.

8. Sherwin E, Sandhu KV, Dinan TG, Cryan JF. May the force be with you: the light and dark sides of the microbiota-gut-brain Axis in neuropsychiatry. CNS drugs. 2016;30:1019-41.

9. Kelly BJ, Gross R, Bittinger K, Sherrill-Mix S, Lewis JD, Collman RG, et al. Power and sample-size estimation for microbiome studies using pairwise distances and PERMANOVA. Bioinformatics. 2015;31(15):2461-8.

10. McDonald D, Birmingham A, Knight R. Context and the human microbiome. Microbiome. 2015;3:52

11. Mattiello F, Verbist B, Faust K, Raes J, Shannon WD, Bijnens L, et al. A web application for sample size and power calculation in case-control microbiome studies. Bioinformatics. 2016:32(13):2038-40.

12. Song SJ, Amir A, Metcalf JL, Amato KR, Xu ZZ, Humphrey G, et al. Preservation methods differ in fecal microbiome stability, Affecting Suitability for Field Studies. mSystems. 2016;1:3.

13. Hill CJ, Brown JR, Lynch DB, Jeffery IB, Ryan CA, Ross RP, et al. Effect of room temperature transport vials on DNA quality and phylogenetic composition of faecal microbiota of elderly adults and infants. Microbiome. 2016:4(1):19.

14. Debelius J, Song SJ, Vazquez-Baeza Y, Xu ZZ, Gonzalez A, Knight R. Tiny microbes, enormous impacts: what matters in gut microbiome studies? Genome Biol. 2016;17(1):217.

15. Paganini D, Uyoga MA, Kortman GAM, Cercamondi Cl, Moretti D, BarthJaeggi T, et al. Prebiotic galacto-oligosaccharides mitigate the adverse effects of iron fortification on the gut microbiome: a randomised controlled study in Kenyan infants. Gut. 2017;66(11):1956-67.

16. Zhang J, Kobert K, Flouri T, Stamatakis A. PEAR: A fast and accurate Illumina paired-end reAd mergeR. Bioinformatics. 2014;30(5):614-20.

17. Caporaso JG, Kuczynski J, Stombaugh J, Bittinger K, Bushman FD, Costello EK, et al. QIIME allows analysis of high-throughput community sequencing data. Nat Methods. 2010;7(5):335-6.

18. McDonald D, Price MN, Goodrich J, Nawrocki EP, DeSantis TZ, Probst A, et al. An improved Greengenes taxonomy with explicit ranks for ecological and evolutionary analyses of bacteria and archaea. ISME J. 2012;6(3):610-8.

19. Edgar RC, Haas BJ, Clemente JC, Quince C, Knight R. UCHIME improves sensitivity and speed of chimera detection. Bioinformatics. 2011;27(16):2194-200.

20. Braak CJF, Smilauer P. Canoco reference manual and user's guide: software for ordination, version 5.0. Ithaca: Microcomputer Power; 2012.

21. Huo W, Zhu W, Mao S. Effects of feeding increasing proportions of corn grain on concentration of lipopolysaccharide in the rumen fluid and the subsequent alterations in immune responses in goats. Asian Australas J Anim Sci. 2013;26(10):1437-45.

22. Gorzelak MA, Gill SK, Tasnim N, Ahmadi-Vand Z, Jay M, Gibson DL. Methods for improving human gut microbiome data by reducing variability through sample processing and storage of stool. PLoS One. 2015;10(8):e0134802.

23. Tedjo DI, Jonkers DM, Savelkoul PH, Masclee AA, Van best N, Pierik MJ, et al. The effect of sampling and storage on the fecal microbiota composition in healthy and diseased subjects. PLoS One. 2015;10(5):e0126685.

24. Dominianni C, Wu J, Hayes RB, Ahn J. Comparison of methods for fecal microbiome biospecimen collection. BMC Microbiol. 2014;14:103.

25. Choo JM, Leong LE, Rogers GB. Sample storage conditions significantly influence faecal microbiome profiles. Sci Rep. 2015;5:16350.

26. Peng $X$, Yu KQ, Deng GH, Jiang YX, Wang Y, Zhang GX, et al. Comparison of direct boiling method with commercial kits for extracting fecal microbiome DNA by Illumina sequencing of 165 rRNA tags. J Microbiol Methods. 2013;95(3):455-62.

27. Larsen AM, Mohammed HH, Arias CR. Comparison of DNA extraction protocols for the analysis of gut microbiota in fishes. FEMS Microbiol Lett. 2015:362(5)

28. Strati F, Cavalieri D, Albanese D, De Felice C, Donati C, Hayek J, et al. New evidences on the altered gut microbiota in autism spectrum disorders. Microbiome. 2017;5(1):24

29. Matsuki T, Watanabe K, Fujimoto J, Takada T, Tanaka R. Use of $16 \mathrm{~S}$ rRNA genetargeted group-specific primers for real-time PCR analysis of predominant bacteria in human feces. Appl Environ Microbiol. 2004;70(12):7220-8.

30. Delroisse JM, Boulvin AL, Parmentier I, Dauphin RD, Vandenbol M, Portetelle D. Quantification of Bifidobacterium spp. and lactobacillus spp. in rat fecal samples by real-time PCR. Microbiol Res. 2008;163(6):663-70.

31. Layton A, McKay L, Williams D, Garrett V, Gentry R, Sayler G. Development of Bacteroides 165 rRNA gene TaqMan-based real-time PCR assays for estimation of total, human, and bovine fecal pollution in water. Appl Environ Microbiol.2006:72(6):4214-24.

Ready to submit your research? Choose BMC and benefit from:

- fast, convenient online submission

- thorough peer review by experienced researchers in your field

- rapid publication on acceptance

- support for research data, including large and complex data types

- gold Open Access which fosters wider collaboration and increased citations

- maximum visibility for your research: over $100 \mathrm{M}$ website views per year

At BMC, research is always in progress.

Learn more biomedcentral.com/submissions 